\title{
Study On Contribution Of Back Plate Shape Of Brake Pad To Disc Brake
}

\section{System Noise}

\author{
PAN Gong-yu, ${ }^{1, a}, J I A N N G$ Zhong-wang ${ }^{1, b}$, YANG Zi-jun ${ }^{2, c}$, SUN Lei ${ }^{2, d}$ \\ 'School Of Vehicle Engineering Jiangsu University, Zhenjiang 212013 ,China \\ ${ }^{2}$ ITT High Precision Machinery Manufacturing , Wuxi 214112,China \\ a774513912@qq.com, ,503902833@qq.com, ${ }^{\mathrm{C}}$ zijun.yang@itt.com
}

Key words: Disc brake,Noise,Back plate,Ansys,Dyno

Abstract: This research focuses on braking pad back plate of disc brake system. Firstly building original 3D model of brake pad and the prototype is manufactured, then 3D model is imported into ANSYS for modal simulation and noise bench test with prototype is conducted. To verify the validity and precision of ANSYS simulation, at the original phase, two cross comparing experiments are made to verify the accuracy of simulation. With laser deformation detector and hammer impact experiment, the natural frequency and vibration modes of brake pad are confirmed. During simulation process, different restriction condition are set based on the different material characteristic of brake pad components which makes the simulation results more accurate. Above two jobs are used to detect the the contribution of back plate to brake noise.Based on simulation and test results, two modifications are done on back plate to change the critical frequency of braking pad,modal analysis and noise bench test are also carried on these two new models. Finally, comparing the results of both two new types braking pads to research the effect of back plate change on disk brake system brake noise. The test result returns that the new design back plate can reduce the occurrence of brake squeal .

With the rapid popularization of automobile in the world,the requirement of vehicle riding comfort is raising, more importance is attached to vehicle $\mathrm{NVH}$ attributes.So far,main noise such as the noise generated by vehicle engine vibration are well handled,secondary noise like brake squeal now is becoming a hot research issue.

Particularly ,most passenger vehicles are applied with two disc brake systems at both front and rear tires,thus, brake squeal deserves more attention.From the 80s of 20 century,more and more scholars start to research brake noise by studying the system structure. This paper focus on the structure change of back plate of brake pad to study the influence on brake squeal . The final result shows that brake pad with structure changed back plate can reduce the occurrence of brake squeal effectively .

\section{Functions of brake pads in disc brake system}

Disc can be divided with two types by the fixed condition of caliper.Take floating caliper disc brake system for example, once the brake pedal is pressed , the oil will go inside cylinder and push the piston4,inner brake pad which is fixed on the piston will contact and compress disc .Meanwhile , the outside pad 6 is pressed on the disc by the caliper body 1, able to slide on its mounts 7 along a direction perpendicular to the disc surface . 

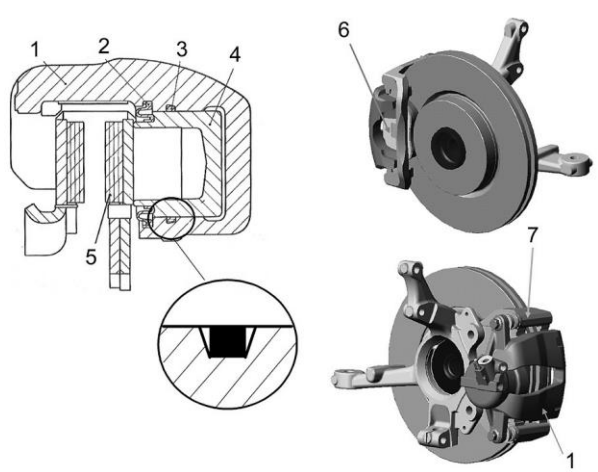

1-Caliper, 2, 3-sealing ring, 4-piston, 5-inner brake pad,

6-outer brake pad, 7-guide bin

Figure 1. Pin slide caliper

With the frictional force, disc will be stopped. During brake process, the bigger brake pad will provide more frictional force to stop the vehicle quickly,however,bigger brake pad leads to bad brake squeal performance ${ }^{[2][3]}$.

\section{Model Building and Simulation}

Typical brake pad are selected from one type vehicle. Firstly, brake pad 3D model will be created in Catia (Fig.2)and imported Ansys to do modal analysis.

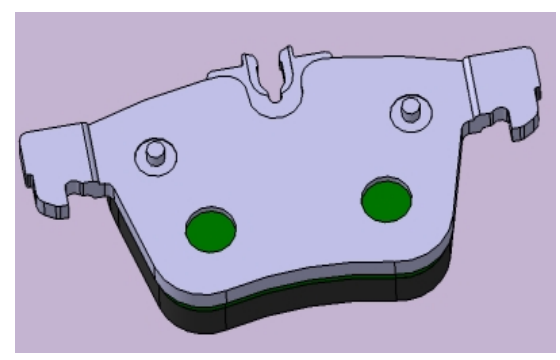

Figure 2. Brake pad 3D model

The solid structure of brake pad is sample and the shape is also ruled, hexahedron mesh is available when meshing the brake pad ${ }^{[4]}$.

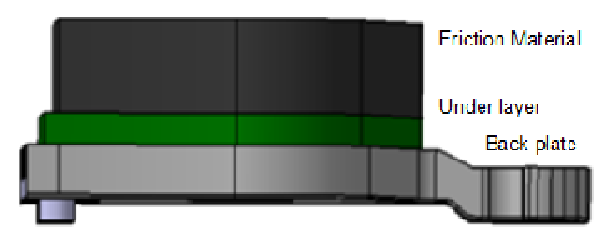

Figure 3. Brake pad components

The brake mainly consists of three parts:back plate,under layer,friction material(Fig 3.).

Most scholars view under layer and friction material as one part,during the analysis process, material definition of brake pad is just divided into two parts simply,back plate and friction material.Actually,the under layer material has more damping property than the friction material,its main ingredients are steel fiber and resin fiber,thus, the material definition should be treated independently when we set the material parameters, otherwise ,this will lead to the wrong simulation result[4].Tab.1 is the material parameters of each part of brake pad. 
Tab 1. Brake pad material parameters

\begin{tabular}{cccc}
\hline Component & Density & Young Modulus & \\
& $\left(\mathrm{g} / \mathrm{cm}^{3}\right)$ & $(\mathrm{Gpa})$ & 0.3 \\
\hline Back Plate & 7.8 & 197 & 0.35 \\
Under layer & 2.8 & 3.35 & 0.32 \\
Friction Material & 2.2 & 4.707 & \\
\hline
\end{tabular}

Modal analysis is conducted at Ansys workbench mode,five typical modal vibration modes(Fig 4.) are selected to further study which are bending and reversing vibration and the natural frequency are within $10000 \mathrm{~Hz}$, Tab 2.

are the natural frequencies ${ }^{[5][6]}$.

To verify the accuracy of simulation analysis,cross comparing experiments are set to check with simulation results which includes with laser detector experiment and hammer impact experiment.

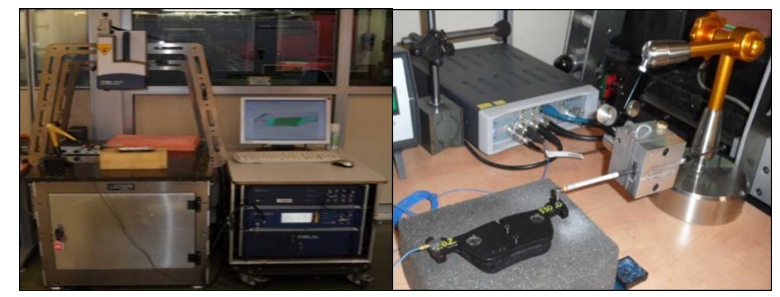

Figure 4. Laser vibration detector and Hammer Impact EXP.

Laser measuring instrument using the principle of optical interference, can measure the small deformation of the experimental object.Based on the fact that the brake pad is much simple,thus ,the laser detector can reproduce the process of the free vibration of brake pad visibly .Fig 5.is the result of laser experiment , Tab 2. is the natural frequency result of laser $\&$ hammer impact experiments.

After comparing the cross analysis, the error of the simulation and experimental results is less than $2 \%$, and the vibration modes are exactly the same as the simulation analysis, Therefore, ANSYS can be used as an effective method to study the noise caused by the vibration of brake pads.

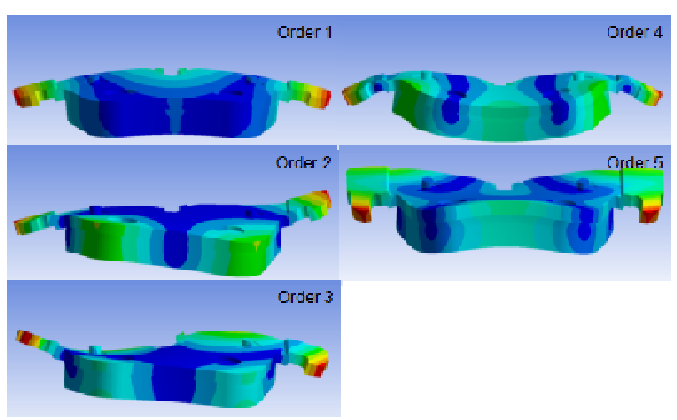

Figure 5. Simulation results 


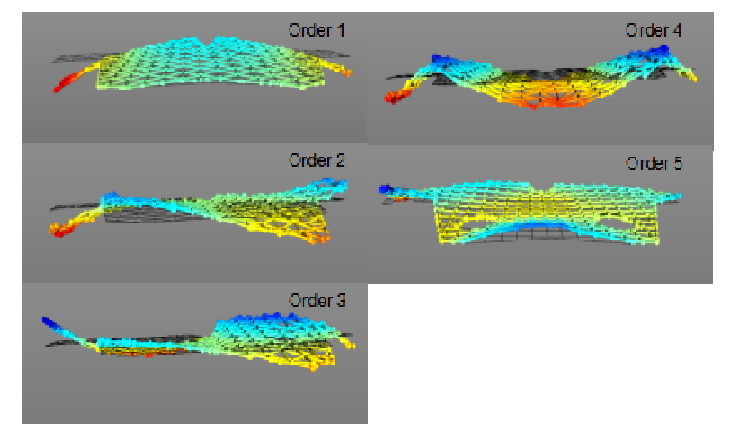

Figure 6. Experiment result by laser detector

The automobile brake disc as a whole composed by a number of parts, so the contribution for each part of the brake noise is different.Thus, in order to study the contribution of the brake pads to the brake noise,the brake noise performance of the vehicle in the driving cycle is simulated,prototype is manufactured to do bench noise test.

Tab 2. Frequency of simulation and experiment

\begin{tabular}{cccc}
\hline Order & Laser(HZ) & $\begin{array}{c}\text { Hammer(H } \\
\text { Z) }\end{array}$ & $\begin{array}{c}\text { Simulation(HZ } \\
\text { ) }\end{array}$ \\
\hline 1 & 3150 & 3151 & 3169 \\
2 & 4195 & 4130 & 4137 \\
3 & 5724 & 5610 & 5689 \\
4 & 7402 & 7268 & 7342 \\
5 & 9601 & 9395 & 9380 \\
\hline
\end{tabular}

The test bench used in this project is LINK3900(Fig 7,Fig 8.).LINK3900 type noise test bench with double cabin structure, can simulate the vehicle on the road in the process of running noise environment, Therefore, the experimental results are close to the real driving process noise distribution.

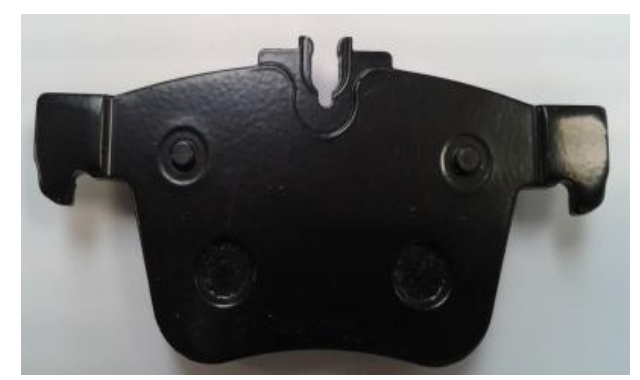

Figure 7. Brake pad prototype 


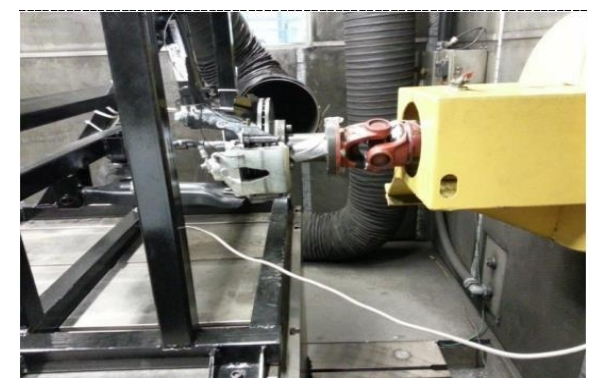

Figure 8. Noise bench test experiment

The experimental control process for the brake noise is set according to the standard of disc brake NVH noise test standard which is published by American Engineering Society, that is, the J2521 SAE experiment standard.

The microphone placed in the brake system horizontal direction from $10 \mathrm{~cm}$, vertical distance $50 \mathrm{~cm}(\text { Fig 9. })^{[7][8]}$.

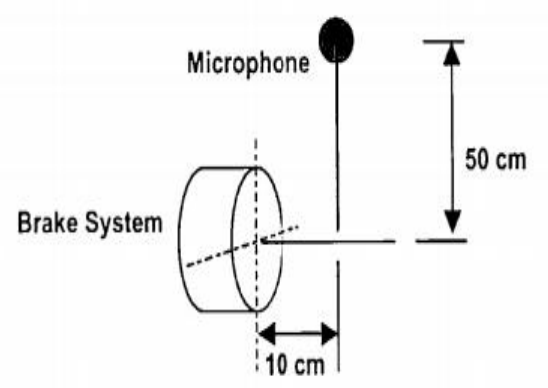

Figure 9. Position of microphone

The results of the experimental results of the test are shown in Fig 10. The noise points are mainly distributed in frequency of the $4 \mathrm{KHz}, 7 \mathrm{KHz}, 12.5 \mathrm{KHz}$.Comparing the experimental results with the natural frequency of the brake pads, The second and the fourth order of the natural frequency of brake pads are $4 \mathrm{KHz}$ and $7 \mathrm{KHz}$, which means these two natural frequencies join the resonance of system leading to the brake noise.Hence,to reduce the brake noise,the effects of the change of back plate on the brake noise of the vehicle are analyzed in this paper.

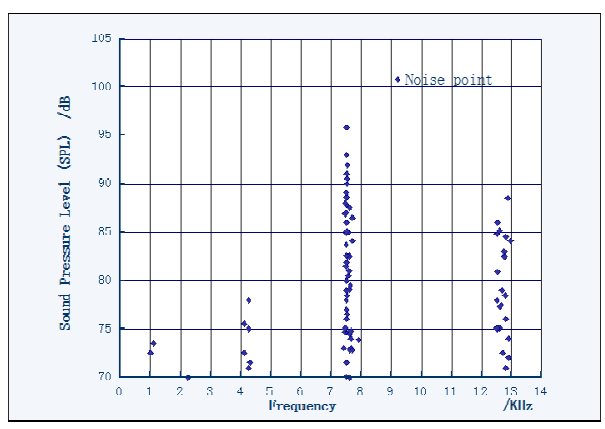

Figure 10. Noise bench test result

\section{Research on the change of back plate}

The purpose of changing the structure of the back plate is to change the inherent frequency of the brake pads. The general way to avoid the resonance of system,increasing or decreasing natural frequency of components are functional methods.After several modification and simulation ,shapes of fig 11 and fig 12 are selected.Due to limit of page,theoretical analysis is not listed ${ }^{[9]}$. 


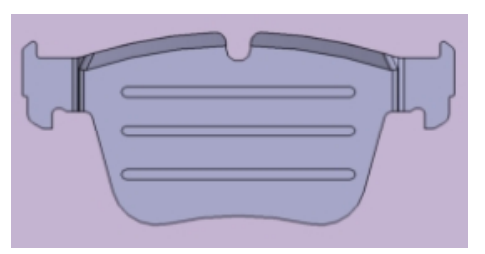

Figure11. Increase key frequency

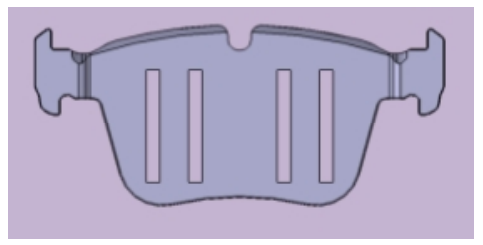

Figure12. Decrease key frequency

The method to increase the natural frequency of the back plate is to process three ribs (Fig 11.)on the back surface of the back plate.Fig 12. is taken at the back surface of the back plate to process four slots to reduce the natural frequency of the steel back.Similar hammer impact experiments and simulations have been done on the two new brake pad with different back plate,the result is shown on Tab3\& 4.

Tab 3. Simulation and experiment result of Frequency increase

\begin{tabular}{ccc}
\hline Order & EXP.(Hz) & Simulation(Hz) \\
\hline 1 & 3220 & 3190 \\
2 & 4085 & 4025 \\
3 & 5637 & 5560 \\
4 & 7518 & 7466 \\
5 & 9368 & 9450 \\
6 & 9644 & 9680 \\
\hline
\end{tabular}

Comparing with the natural frequency of previous brake pad,the changes are $\Delta 1=112 \mathrm{~Hz}, 124 \mathrm{~Hz}$. $\Delta 2=-328 \mathrm{~Hz},-430 \mathrm{~Hz}$.

Tab 4. Simulation and experiment result of Frequency decrease

\begin{tabular}{ccc}
\hline Order & EXP.(Hz) & Simulation(Hz) \\
\hline 1 & 2960 & 2920 \\
2 & 3856 & 3809 \\
3 & 5401 & 5379 \\
4 & 6895 & 6912 \\
5 & 8549 & 8678 \\
6 & 9398 & 9431 \\
\hline
\end{tabular}

Bench tests are needed for the noise performance of disc system to study the influence caused the change of by back plate 


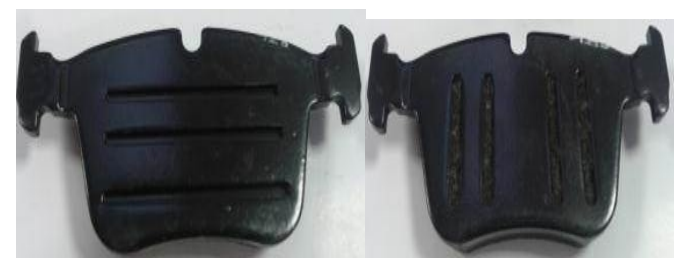

Figure 13. Prototype after modification

all the experiment conditions such as disc,caliper,standard control programs are exactly same with the first one.The results are shown on Fig 14. \&Fig 15.

It returns from the experimental result that the brake pad with three ribs back plate can effectively reduce the occurrence of automobile brake noise, brake pads didn't have resonance with other parts in disc brake system, several

noise points are caused by the external factors,such as temperature, humidity or $\mathrm{DTV}^{[9]}$. However, the other brake pad with four slots back plate is unable to reduce the occurrence of brake noise, brake squeal still exists at $4 \mathrm{KHz} \& 7 \mathrm{KHz}$.

Therefore, with different shape back plate ,brake pads for automobile brake noise real exist in varying degrees of impact.

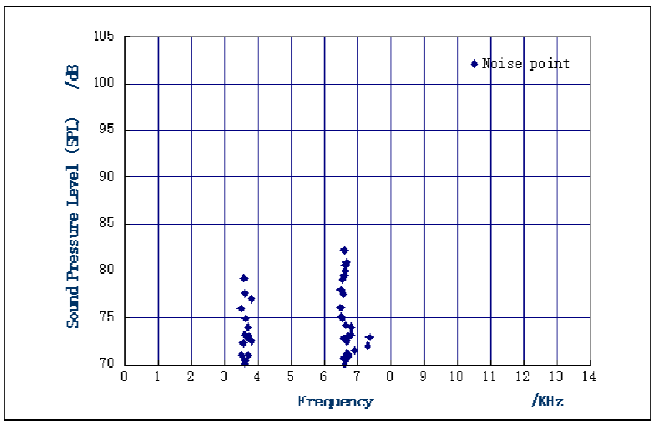

Figure 14. Noise bench test(Four slots)

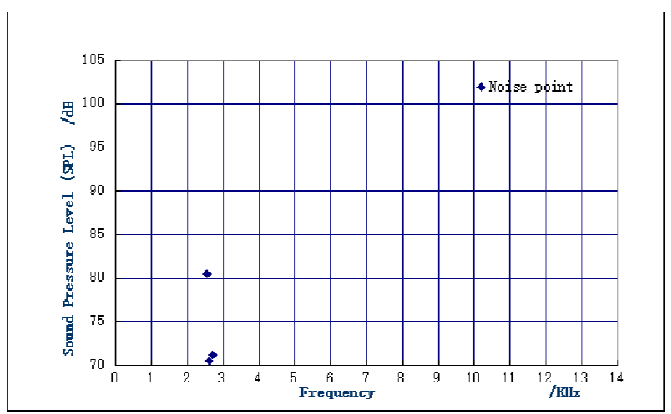

Figure 15. Noise bench test(Three ribs)

\section{Conclusion}

The simulation analysis and experimental results on brake pads indicate:The structure change of brake pad back plate will greatly affect disc brake noise.By the method proposed in this paper, changing and optimizing back plate structure which will decrease or increase the critical natural frequency can reduce the occurrence of disc brake squeal.However,the application of this method still needs to be improved, this is because the strength of back plate is affected due to modification, which brings potential risk in the application,this can be solved by using different back plate material ,but from the point of view of the method proposed in this paper, this method 
provides a reliable theoretical basis for the design of braking system.Due to the limit of pages, the theory analysis can't be displayed on this paper

\section{Reference}

[1] Guan Di-hua, Su Xu-dong. Review the Development and analysis of braking noise [J]. Engineering mechanics.2004,21(4):150-155

[2] Lv-Honmging,Zhang-LJ.A review of Automotive disc brake squeal [J].Journal of Vibratio n and shock.2011,30(4):1-5 [3] G.Gentaandl.Automotive Chassis Volume1: Components Desi gn [M].USA:Media B.V 2009

[4] Liu Ai-jun Research on vibration character of brake pad and shim in vehicle braking sy stem [D].Wuhan:Wuhan science and engineering university,2009

[5] Ma'rio Triche^sJu'nior, Samir N.Y. Gerges.Analysis of brake squeal noise using the finit e element method: A parametric study[J].Applied Acoustics . 2008,69 (1) :147-162.

[6] Jae young Kang.Finite element modelling for the investigation of in-plane modes and da mping shims in disc brake squeal [J].Journal of Sound and Vibration 2012 ,331(2) 2190-22 02

[7] The SAE Dynamometer Test Code Committee. Disk Brake Dynamometer Squeal Noise Matrix. SAE J2521[S].USA: SAE,2013

[8] Noise Vibration Harshness\&Disc Thickness Variation / Judder .ITT BOOK [S].Italy:ITT , 2000

[9] Meng-DJ,Zhang-LJ.Analysis on affection of Muti-points contact model of original SRV a nd DTV on brake vibration [J]. Journal of Vibration and shock.2011,30(4):1-5 